\title{
Europe's Path to Net Zero Emissions
}

The European Union has set an ambitious target to reduce net greenhouse gas emissions to zero by 2050 , while at the same time ensuring economic and social sustainability. The European Green Deal lays out a path towards realising this target, accelerating policy change that touches upon many aspects of the economy and society. What are the main challenges to the implementation of the European Green Deal? What are the costs and benefits of decarbonisation? Which industrial policy is needed to turn decarbonisation into an economic opportunity for Europe? How to finance the transition to a low-carbon economy? Which trade policy instruments could create incentives for more climate protection? This Forum seeks to answer these questions, discussing the key issues and reviewing the different policy perspectives on climate change mitigation in the European Union.

Fostering the Industrial Component of the European Green Deal: Key Principles and Policy Options

Simone Tagliapietra, Bruegel, Brussels, Belgium; and Università Cattolica del Sacro Cuore, Milan, Italy.

Reinhilde Veugelers, University of Leuven, Belgium; and Bruegel, Brussels, Belgium.

Carbon Border Adjustment and Other Trade Policy Approaches for Climate Protection

Galina Kolev, RheinMain University of Applied Sciences, Wiesbaden; and German Economic Institute (IW), Cologne, Germany.

Green Hydrogen in Europe: Do Strategies Meet Expectations?

André Wolf, Hamburg Institute of International Economics (HWWI), Germany.

Nils Zander, Hamburg Institute of International Economics (HWWI), Germany.

Green Finance in Europe - Strategy, Regulation and Instruments

Volker Brühl, Center for Financial Studies, Frankfurt, Germany.

Europe's Climate Target for 2050: An Assessment

Richard S. J. Tol, University of Sussex, Falmer, UK; and Vrije Universiteit, Amsterdam, The Netherlands. 